\title{
CUIDADO HUMANIZADO EM TERAPIA INTENSIVA: UM ESTUDO REFLEXIVO
}

\author{
Humanized Care in Intensive Therapy: \\ a Reflexive Study \\ Cuidado Humanizado en Terapia Intensiva: \\ un Estudio Reflexivo
}

\author{
Joselany Áfio Caetano \\ Luciene Miranda de Andrade
}

Enedina Soares

Roberta Maria da Ponte

\section{Resumo}

Objetivou-se neste estudo conhecer o significado da assistência humanizada prestada a pacientes em tratamento intensivo sob a ótica de dezessete profissionais de saúde que trabalhavam na Unidade de Terapia Intensiva de um hospital filantrópico situado na região metropolitana da cidade de Sobral - CE, Brasil. Para a coleta de dados, utilizou-se um instrumento contendo a seguinte pergunta: Qual o significado da humanização da assistência para você? Dos dados emergiram três categorias de análise: conforto emocional; confor to físico e compromisso profissional, cuja análise revela a melhoria da assistência não configurada nos avanços da tecnologia, mas, em valores pessoais, na compreensão do verdadeiro significado do cuidado, o direcionamento da assistência ao conforto físico e emocional associado ao cuidado que visa amenizar a dor; cuidar com compromisso aplicando a prática humanística. Conclui-se que o processo de cuidar humanístico leva os profissionais a refletir acerca das suas posturas pessoais e acadêmicas, fortalecendo sempre o trabalho em equipe.

Palavras-chave: Humanização da Assistência. Unidades de Terapia Intensiva. Exercício Profissional.

\begin{abstract}
This study aimed to know the meaning of humanized care give to patients in intensive therapy, from the perspective of seventeen health professionals who worked at the Intensive Therapy Unit of a philanthropic hospital in the metropolitan region of Sobral city - Ceára, Brazil. The data was collected through an instrument with the following question: What does humanized care mean to you? Three analytic categories emerged from data: emotional comfort; physical comfort and professional commitment, whose analysis reveals the improvement of care, which is not configured in technological advances, but in personal values, in the understanding of the true meaning of care, the orientation of care towards physical and emotional comfort, associated with care aimed at relieving pain; care with commitment, applying humanistic practice. It is concluded that the humanistic care process makes professionals reflect about their personal and academic attitudes, always strengthening team work.
\end{abstract}

Keywords:

Care Humanization. Intensive Care Units. Health Professionals.

\section{Resumen}

Se objetivó en este estudio conocer el significado de la asistencia ofrecida a los pacientes en tratamiento intensivo sobre la óptica de los diecisiete profesionales de salud que trabajó en la Unidad de la Terapia Intensiva de un hospital filantrópico situado en la región próxima de la ciudad de Sobral - Ceará, Brasil. Para la colecta de datos se utilizó una herramienta conteniendo la siguiente pregunta: ¿Cuál es el significado de la humanización de asistencia para usted? Los datos recogidos, emergieron en tres categorías de análisis: confor to emocional; confor to físico y compromiso profesional, el análisis señaló la mejoría de la asistencia no configurada en los avances de la tecnología, todavía en valores personales y la comprensión del verdadero significado de la atención y en el direccionamiento de la asistencia al confor to físico y emocional asociado al cuidado que mira la reducción del dolor; cuidar con el compromiso aplicándola en la práctica humanitaria. Se concluye que el proceso es un reflejo a los profesionales a respecto de sus posturas personales y además académicas, fortaleciendo siempre el trabajo en equipo.

Palabras clave: Humanización de la Atención. Unidades de Terapia Intensiva. Profesionales de salud. 


\section{INTRODUÇÃO}

Atualmente estamos vivenciando no cotidiano hospitalar vertiginoso desenvolvimento tecnológico de procedimentos diagnósticos e terapêuticos. Esses avanços tecnológicos vêm contribuindo para a melhoria da assistência, com ênfase nas unidades críticas, particularmente nos serviços de terapia intensiva.

A Unidade de Terapia Intensiva (UTI) é tida como um local onde se presta assistência qualificada especializada, independentemente de os mecanismos tecnológicos utilizados serem cada vez mais avançados, capazes de tornar mais eficiente o cuidado prestado ao paciente em estado crítico. Esse setor é constituído de um conjunto de elementos funcionalmente agrupados, destinado ao atendimento de pacientes graves ou de risco que exijam assistência médica e de enfermagem ininterruptas, além de equipamentos e recursos humanos especializados ${ }^{1}$.

Ante essas mudanças e com vistas ao desenvolvimento do conhecimento da equipe de saúde, se faz necessária uma reflexão das ações realizadas no cotidiano, e, conseqüentemente, mais preparo dos profissionais, não só sob o aspecto teórico e técnico, mas, também, voltada à transformação da assistência numa perspectiva mais humanitária.

Há de se questionar a importância da existência de um local onde a tecnologia possa ser colocada à disposição da manutenção da vida humana, onde a observação possa ser tão constante e intensiva que muitas situações limites possam ser revertidas a favor da vida ${ }^{2}$. Acrescente-se ainda ser preciso refletir até que ponto o progresso tecnológico como se verifica hoje é "saudável" e promove o crescimento e a harmonização das pessoas. Esta polêmica é constante, e, conforme percebemos quando questionamos os próprios profissionais da área de saúde, nenhum deseja a UTI para si mesmo ou para seus entes queridos. Todos preferem, quanto muito, morrer "dormindo", em casa, de repente, sem dor.

De modo geral, em termos de desenvolvimento e aperfeiçoamento tecnológico, vivemos uma nova realidade jamais imaginada. Não se trata de condenar a tecnologia. Esta, em si mesma, não é benéfica nem maléfica-, pois tudo depende da forma como a usamos. A tecnologia deve ser utilizada de forma criativa e humana para melhorar a qualidade de vida.

A qualidade de vida tem sido estudada em seus múltiplos aspectos. Assim, ao fazermos uso do termo qualidade de vida, este implica um processo de avaliação de como se vive, e, conseqüentemente, do contexto em que se processa este viver e dos seus componentes, sob a ótica do usuário dos nossos serviços (cliente, família e comunidade) e sob a nossa ótica profissional, permeada pelos significados atribuídos coletivamente no tempo e no espaço. Pode ser considerado, também, um indicador competente do resultado dos serviços de saúde prestados ao cliente, principalmente por ser determinado pelo processo da doença ou agravo em si, como pelos procedimentos utilizados para o seu tratamento ${ }^{3}$.

Os profissionais de UTI e, de modo especial, o enfermeiro, devem estar conscientes de que o objetivo final do seu trabalho é o cuidado. Isto não significa termos de garantir a manutenção da vida, pois o maior conhecimento deve nos capacitar para a identificação de prognósticos mais precisos da morte, na descoberta de analgésicos mais poderosos capazes de controlar a dor, e ainda na aquisição de fundamentos psicológicos mais poderosos para aliviar a ansiedade e o sofrimento.

Resgatar a humanidade nas UTIs talvez seja voltar a refletir, sempre mais conscientemente, sobre o que é o ser humano. A UTI precisa e deve utilizar-se dos recursos tecnológicos cada vez mais avançados, mas os profissionais desta unidade jamais devem esquecer que a máquina não substituirá a essência humana ${ }^{4}$.

Na literatura, o cuidado tem sido abordado como ontológico, epistemológico, ético, como uma metodologia de investigação, uma prática organizacional. As definições do cuidado têm abrangido tanto a concreta função do "fazer", as formas de conhecimento e de investigação, como as formas de "ser". Elas têm sido ligadas ao contexto transcultural, com uma abordagem feminista em direção ao conhecimento e desenvolvimento de novas formas de consciência. 0 reconhecimento da importância do cuidado reflete-se no oferecimento de uma assistência com qualidade, isto é, atender perfeitamente, de forma confiável, segura e no tempo certo às necessidades do cliente ${ }^{5}$.

0 conceito de vida na literatura sugere uma luta constante para vencer o abismo entre saber o que fazer e fazê-lo de fato. Humanizar na UTI é voltarmos a refletir sobre o ser humano, começando pela própria vida dos nossos parceiros, da nossa equipe e, conseqüentemente, dos nossos pacientes?

A nosso ver, somente é possível humanizar UTIs mediante nossa própria humanização. Os enfermeiros, por exemplo, não podem humanizar 0 atendimento do paciente crítico antes de aprenderem a serem íntegros consigo mesmos. Não podem "deixar" parte de si em casa e assumir comportamentos diferentes que o tencionem por não poder ser ele mesmo. 0 encontro com o paciente nunca é neutro. Por isto, 0 enfermeiro deve reconhecer que sua presença é tão importante quanto o procedimento técnic $0^{6}$.

$\mathrm{Na}$ condição de enfermeiros intensivistas, vivenciamos a prática dos profissionais de saúde que trabalham com pacientes críticos, a maneira como as rotinas são incorporadas por estes, refletindo-se diretamente no cuidado de forma positiva. Os pacientes admitidos são observados continuamente pela equipe de saúde. Além disso, há disponibilidade de aparelhos sofisticados vistos negativamente, por acarretarem maior ônus para a família, falta de privacidade, constância da morte, incômodo produzido pelos ruídos dos aparelhos, luzes e clima frio, desconforto ocasionado pela rotina do cuidado. Conforme observamos, as ações desenvolvidas pelos profissionais de saúde apresentam enfoque mais técnico do fazer, e eles esquecem o cuidar como uma característica humana, baseada na afetividade, no conhecimento de valores, habilidades e atitudes empreendidas no sentido de favorecer as potencialidades dos pacientes para manter ou melhorar a condição humana no processo de viver e morrer.

Não resta dúvida de que, apesar de todo esforço despendido pelos membros da equipe para humanizar a UTI, esta é uma tarefa difícil, pois demanda, às vezes, atitude individual em relação a um sistema tecnológico dominante. A própria 
dinâmica de uma UTI muitas vezes impede momentos de reflexão sobre a devida orientação dos profissionais aí atuantes. Para humanizar a assistência em UTI, é necessário, sobretudo, nela se abrir espaço para discussão sobre a morte e o morrer?

Humanizar não é técnica ou artifício, mas, sim, um processo vivencial a permear toda atividade dos profissionais no intuito de realizar e oferecer o melhor tratamento ao ser humano, dentro das circunstâncias peculiares vividas em cada momento do hospital ${ }^{6}$.

Nos últimos tempos, a humanização em Unidade de Terapia Intensiva tem sido um assunto bastante abordado, em decorrência da constante preocupação dos profissionais da saúde em oferecer uma assistência de qualidade. Com esta finalidade, propõem como foco central o atendimento das necessidades individuais dos pacientes, fortalecido pelo contato mais próximo com familiares, os quais, acredita-se, podem influenciar decisivamente no processo de cura e reabilitação.

Como estratégia válida e desejável, a humanização possui nova tendência de sinalizar as sensações e impressões subjetivas dos profissionais que atuam nas UTIs, qual seja, a excelência técnica, isoladamente, embora necessária, não é suficiente para alcançar a recuperação do paciente crítico em sua plenitude biopsicossocial. Assim, calor humano, privacidade e individualidade, respeito ao pudor das pessoas, preservação do conforto e bem-estar físico e mental, proximidade entre pacientes e familiares, possibilidade de acesso às informações, de ser ouvido e sentir-se participante do esquema terapêutico proposto são alguns dos elementos que se fundem para atenuar 0 ambiente inóspito das UTIs tradicionais ${ }^{4}$.

0 presente estudo procura envolver a equipe para descobrir meio e forma de relacionamento, permeado pela humanização, pois trabalha os motivos, valores e atitudes ao lado dos fenômenos não quantificáveis. A partir daí, é possível obter o significado dos acontecimentos vividos pelos profissionais e pacientes. Para isto, delineamos o seguinte objetivo: conhecer o significado da assistência humanizada a pacientes em tratamento intensivo sob a ótica dos profissionais de saúde que atuam em UTI.

\section{METODOLOGIA}

Trata-se de um estudo descritivo com abordagem qualitativa, realizado na Unidade de Terapia Intensiva de uma instituição filantrópica de Sobral - CE, integrada ao Sistema Único de Saúde (SUS), caracterizada como instituição geradora e capacitadora de recursos humanos voltados para o ensino, pesquisa e extensão, e tendo como objetivos a assistência qualificada, diversificada, especializada e humanizada no cuidar.

Os sujeitos deste estudo foram dezessete profissionais de saúde que trabalhavam na UTI durante o segundo semestre de 2004, assim especificados: oito médicos, seis enfermeiras, três fisioterapeutas.

Conforme determinado, este estudo considerou as diretrizes e normas regulamentadoras de pesquisa envolvendo seres humanos, incorporando os quatros referenciais básicos da bioética: a autonomia, a partir da utilização do termo de consentimento livre e esclarecido dos sujeitos; a beneficência, ponderada entre riscos e benefícios, comprometendo-se com o máximo de benefícios e o mínimo de danos e riscos; a nãomaleficência, garantindo que danos possíveis sejam evitados; e a equidade e justiça, envolvendo a relevância social da pesquisa com vantagens significativas para os sujeitos do estudo ${ }^{8}$. Com vistas a garantir 0 anonimato dos participantes, usamos as letras: $E$ (enfermeiro), $F$ (fisioterapeuta), M (médico), e seus respectivos números.

Para o desenvolvimento deste estudo utilizamos uma questão norteadora: Qual o significado da humanização na assistência para você? 0 instrumento foi entregue aos participantes do estudo, com um prazo de retorno preestabelecido, para possibilitar mais oportunidade de reflexão sobre a temática em discussão ${ }^{9}$. Os discursos escritos foram agrupados em categorias de análise.

\section{APRESENTAÇÃO E ANÁLISE DOS RESULTADOS}

Após a revisão da literatura e em segmento à proposta do estudo, passamos a analisar o conteúdo dos discursos escritos acerca da compreensão sobre humanização da assistência prestada ao paciente em terapia intensiva pelos profissionais de saúde. Da análise dos discursos escritos emergiram três categoriais: conforto emocional, conforto físico e compromisso profissional.

\section{Conforto emocional}

Nesta categoria conforto, apesar de ser subjetivo, multifatorial e pessoal, na maioria das vezes se refere não só aos procedimentos, às tecnologias e aos medicamentos adotados na recuperação, mas também aos aspectos interacionais e humanos do cuidado. A dimensão interacional traduzida na forma de atenção, cortesia, delicadeza, prontidão, solicitações e comunicação efetiva está bem clara nos discursos como determinantes de necessidade do paciente. Nesse caso, o confor to emocional é entendido como:

0 doente precisa muito de medicamentos, mas precisa também ser tratado com carinho, respeito, dignidade e com responsabilidade (M. 1).

Minimizar o estado de depressão através de palavras de carinho, incentivo e de fé, paciência e solidariedade e atendimento afetuoso a pacientes que passam por este setor (M. 2).

É tão importante quanto as medicações e procedimentos instrumentais que utilizamos no cotidiano (M. 3).

Cuidar, conversar e ouvir, pôr-se em seu lugar. Saber ouvir e ajudar os familiares (E. 1).

Gesto e carinho de servir em todas as dimensões: físicas, psíquicas e espirituais, desconsiderando interesses materiais (E. 2).

Respeitar o paciente, suas necessidades, limites, crenças, tabus, aliviando assim suas perspectivas e ansiedades para sua recuperação, atendendo melhor os familiares, não esquecendo as normas e rotinas do setor (E. 3). 
Aproximar-se dos pacientes através de conversas amigáveis que levam à failitação do trabalho prestado, tornando-o mais confiante, funcionando como uma alternativa terapêutica $(E .1)$.

Servir e tratar os pacientes com amor, dedicação, atenção, levar palavras de conforto para que se sintam seguros e confiantes na assistência prestada (E.5).

Segundo os discursos, o conforto emocional é importante em vários aspectos. Contudo, como indispensáveis ao tratamento, sobressaem os seguintes: a prescrição e a administração da terapia medicamentosa; é necessário também cuidar do paciente com carinho, dedicação, respeitá-lo como ser humano, considerando suas crenças, valores, desejos e expectativas quanto à internação e evolução do estado de saúde. Desenvolver o cuidado com a responsabilidade de minimizar o quadro de depressão e angústia instaladas no paciente em virtude da sua permanência na UTI mediante estabelecimento de um diálogo, quando possível, levando palavras de incentivo e fé no intuito de conquistar a confiança do paciente e do familiar.

Particularmente no tratamento de pacientes críticos, a humanização é tão importante quanto a medicação e os procedimentos instrumentais utilizados durante 0 trabalho. Entretanto, às vezes, conforme percebemos, prioriza-se a terapia baseada em tecnologia de maior custo em detrimento do humanismo.

Quando usamos a tecnologia em favor do bem-estar do paciente, ele passa a valorizá-la como uma aliada na tentativa de preservar-lhe a vida, o bem-estar, o conforto. Os pacientes são levados para a UTI para receber cuidados qualificados exercidos por uma equipe de saúde também qualificada. Esta unidade é uma área física dotada de materiais e equipamentos especiais com vistas a proporcionar 0 atendimento numa situação limite?

Diante das muitas circunstâncias e observações, a equipe trabalha personalizando os pacientes, tratando-os pelo primeiro nome. Em cada boxe existe um painel contendo nome e sobrenome, procedência e diagnóstico médico. A despeito destes cuidados, em virtude de se tratar de um ambiente fechado e com acesso familiar restrito e de curta duração, na UTI o paciente sente-se extremamente só, abandonado, cercado por estranhos e com tendência a desorientação e depressão.

Por ser um ambiente onde se encontram vários indivíduos portadores de doenças distintas, em condições também distintas, como os que desenvolvem quadro satisfatório condizente com a saída da unidade, enquanto outros lá permanecem ou têm prognóstico indefinido, é preciso particular atenção sobre eles. Diante da experiência, os indivíduos que saem da UTI talvez passem por profundos momentos de reflexão sobre a proximidade com situações de risco, pois viram a morte de perto. Isto certamente os faz valorizar a vida.

Freqüentemente os fatores estressantes, presentes na UTI, provocam nos pacientes reações psicológicas indesejáveis, como 0 medo, a ansiedade, a insegurança e a depressão. Essas reações podem reduzir, ou mesmo anular, os efeitos benéficos do tratamento intensivo. A maioria delas, no entanto, pode ser evitada se a equipe da UTI se mantiver atenta, identificando as causas que as determinam e procurando eliminá-las. Uma das medidas essenciais para minimizar o desconfor to psíquico do paciente é informá-lo sobre suas condições e sobre a assistência a ele prestada. Portanto, na assistência em UTI são fundamentais a identificação $\mathrm{e} o$ atendimento das necessidades dos pacientes bem como das suas expectativas quanto aos cuidados ${ }^{10}$.

Todo exercício profissional exige competência técnica. Mas somente esta competência não é suficiente para garantir um cuidado de qualidade. Embora esse tipo de competência proporcione a correta execução de procedimentos técnicos, de acordo com os princípios que os regem, a principal característica do cuidado é a maneira como ele é realizado. Essa maneira é evidenciada pela competência emocional, ou seja, pelo saber lidar com suas emoções em contato consigo e com o outro. São habilidades aprendidas informal ou formalmente ${ }^{11}$.

Existem inúmeras maneiras de interagir com o ser humano; assim, um olhar, um sorriso, um gesto, um deslocamento físico de aproximação ou afastamento, constituem formas de interação entre pessoas ${ }^{12}$.

0 resgate da essência do cuidado mediante interação reafirma a importância do trabalho da equipe. Por exemplo: dar um banho é diferente de banhar o corpo de uma pessoa; dar medicação para dor de cabeça é diferente de cuidar da cabeça doída de uma pessoa ${ }^{11}$.

Para compreender o paciente sob seus cuidados, o profissional precisa se aprofundar em reflexões, contemplação e discussões relacionadas à compreensão do ser. Tanto o autoconhecimento como a autopercepção e a autoaceitação de si mesmo são importantes para poder o profissional vivenciar subjetivamente 0 cliente, tornando-o sensível à condição humana ${ }^{13}$.

Uma das exigências a ser considerada é a da família. Isto é fator normal, pois é o psicológico deles que está abalado. Eles têm necessidade de saber tudo, mesmo se não entenderem muita coisa. 0 desejo das informações, a certeza da presença de um profissional junto do paciente thes proporciona mais alívio, conforme mostram os discursos escritos:

Encontrar um ponto de equilibrio entre as regras rígidas de um sistema hospitalar e a integração da família no processo saúde-doença (F. 1).

Amenizar o sofrimento do paciente e familiar por meio da segurança, respeito e amor repassados pelo profissional, não só através da manipulação de técnicas, mas também na técnica do sentimento (E.6).

Neste estudo, o conceito de humanização foi lembrado em quase todas as falas, traduzindo 0 ato de cuidar, servir e tratar dos pacientes de forma afetuosa. 0 cuidado é prestado por toda a equipe da unidade, mas, principalmente, pelos profissionais de enfermagem responsáveis diretos pela freqüência e dinâmica deste cuidado. A eles cabe desenvolver cuidados específicos com o paciente, tais como: preparação e administração de medicamentos, monitorização dos sinais vitais, banho no leito, higiene corporal obedecendo a técnicas e proporcionando a privacidade do cliente.

\section{Conforto físico}

Confor to e saúde são palavras do senso comum: todos têm uma noção do seu sentido, entendem do que se está falando. Confor to é a comodidade ou a sensação de bem-estar físico. $\mathrm{Na}$ prática, tanto saúde como conforto costumam ser definidos por seus opostos: saúde como ausência de doença e conforto 
como ausência de sensações desagradáveis ${ }^{14}$. Na esfera física corporal, entende-se conforto como o não-aparecimento de dor ou qualquer outra situação desconfortante. Pelos sujeitos do estudo, esta categoria foi definida como:

Promover a cura física do cliente a fim de diminuir seu sofrimento (E. 3).

Visar mais pelo atendimento das necessidades de conforto físico tais como: prótese ventilatória bem sintonizada com o paciente, eliminação total da dor, mobilização do paciente no leito, posicionamento adequado de sondas nasogástrica e vesical, aspiração freqüente de sangue e secreções, higienização, evitar desconforto proveniente de materiais invasivos (catéteres, tubo orotraqueal, drenos, etc.) (M. 4).

Preocupar-se com suas queixas, procurando confortálos da melhor maneira possível já que estão vivendo um momento de fragilidade e sofrimento, necessitando de toda atenção (E. 4).

Conforme os relatos evidenciaram, a promoção do conforto físico é muito importante na situação assistencial, e todos os membros da equipe devem trabalhar de forma eficiente e integrada. Cuidar do paciente crítico representa uma excelente oportunidade de pôr em prática não só os fundamentos técnicos tão necessários aos profissionais de saúde neste cenário de complexidade, mas, também, as reflexões imprescindíveis para um cuidar que visualiza o homem como um sujeito integrante desta ação ${ }^{11}$.

Uma preocupação comum dos profissionais da UTI é o direcionamento do cuidado ao conforto físico. Este é associado à prestação de cuidados destinados a amenizar a dor e o sofrimento do paciente por meio da cura física do corpo. 0 estranho maquinário, as constantes privações, interrupções e privação de sono, a superestimulação sensorial, sede, dores, abstinência de alimentos comuns, a alimentação endovenosa ou nasoenteral, a respiração por ventiladores, a monitorização cardíaca e sua sinalização, os catéteres, procedimentos invasivos, a imobilização do paciente e ainda a superlotação de equipamentos no local, tudo isso equivale a desencadeantes para situações que propiciam alterações psicopatológicas e intenso desconforto físico.

Fica claro nos depoimentos dos participantes do estudo que a dimensão técnica no cuidado é indiscutível, principalmente num ambiente como a UTI, onde manter a vida ou interrompê-la pode ser decidido em razão desta unidade. Nesse aspecto, o profissional de UTI precisa estar tão preocupado e atento às necessidades fisiológicas básicas que, às vezes, pode achar ter cumprido seu dever com o paciente, mesmo quando não o cumpriu.

\section{Compromisso profissional}

0 compromisso profissional se constitui no exercício do conhecimento aplicado à prática visando à promoção da saúde. Oferecer condições de atendimento, onde a equipe possa desempenhar um papel fundamental para o paciente (E. 4).

Buscar a excelência no atendimento para melhorar a qualidade de vida do paciente internado (F. 2).

Desenvolver o trabalho com competência e habilidade técnica e humana que corresponda às necessidades dos pacientes (M. 5).
Luta constante para vencer o abismo entre o que fazer e fazê-lo de fato; é voltarmos a refletir sobre o ser humano, começando pela própria vida dos nossos parceiros, nossas equipes e nossos pacientes (E.5).

A análise desses discursos escritos de alguns profissionais participantes deste estudo revela o significado da assistência humanizada como uma forma de compromisso com a profissão. Como evidenciado, a disponibilidade de condições de assistência abrange aspectos importantes para o exercício da atividade a ser desempenhada. Entre estas, mencionamos: o profissional deve dispor de ambiente adequado, com estrutura física programada para atender os doentes; de equipe multidisciplinar, a fim de prover atenção dinâmica e sistematizada; de materiais e equipamentos sofisticados; de medicação suficiente para suprir a demanda do serviço; de equipamentos de proteção individual para efetivar o cuidado; de conhecimento científico e técnico, com vistas a atuar com base em razões científicas; e de recompensa financeira para satisfação profissional.

De modo geral, as exigências do trabalho em UTI situamse nas dimensões intelectual, motora e expressiva, buscando, por meio destas, a excelência no atendimento a fim de melhorar a qualidade de vida do paciente enquanto se completa o período de internação na unidade.

Como profissional do humano, cuja matéria-prima para o exercício da profissão é o próprio homem e toda sua peculiaridade no existir, seja ela qual for, não se deve antever ou mesmo pré-conceituar suas necessidades. É preciso, num processo de interação e reciprocidade de perspectivas, captar e planejar conjuntamente o que deve ser feito ${ }^{11}$. 0 compromisso com a profissão estimula a convivência harmoniosa e produtiva em um ambiente caracterizado pela negatividade, considera a padronização de rotinas, a definição de funções e tarefas, o treinamento e a educação continuada, a organização profissional valorizando o trabalho em equipe, ou seja, a interação interdisciplinar.

Conforme mostra o dia-a-dia, o grande elemento facilitador da melhoria dos processos de prestação de serviços é, justamente, o investimento na participação e experiência do pessoal que apóia ou realiza tarefas finais, quer sejam plantonistas, diaristas ou demais profissionais: é a denominada cultura organizacional orientada para garantia e melhoria da qualidade 4 .

Portanto, os profissionais de saúde devem contemplar seu cotidiano na busca de caminhos que vislumbrem o alcance de novas perspectivas do fazer. 0 exercício da profissão é um compromisso com o paciente em estar presente sempre que possível, atendendo às suas indagações e inquietações. É a contínua dedicação ao ato do fazer inesgotável, na vontade de superar a morte, apoiando-se na solidariedade e na ética. É importante pensar como se processa a produção desse conhecimento e as implicações subjetivas geradas pelos efeitos do conflito entre o paradigma realista positivista e os novos deveres que emergem da complexidade do cuidado. Este cuidado envolve prudência, dedicação, lealdade, confiança, humildade, esperança e ética. 


\section{CONSIDERAÇÕES FINAIS}

Neste estudo procuramos conhecer o significado da humanização do cuidado prestado ao cliente na UTI sob a ótica dos profissionais de saúde. Segundo observamos por meio do olhar expresso pelos profissionais, a humanização compreende desde o confor to emocional até o confor to físico e compromisso profissional.

Para os profissionais de saúde, especificamente os que convivem e trabalham em unidade de terapia intensiva, ressaltamos a impor tância de visualizar a assistência em limite mais amplo do que o descrito por eles. É preciso estar sempre em busca de novos conhecimentos, com vistas a qualificar a assistência e partilhar seus conhecimentos com a equipe de trabalho, numa visão voltada para o ser humano. Urge buscar alternativas para melhorar a assistência ao cliente,

\section{Referências}

1. Nascimento AR, Caetano JA. Pacientes de UTI: perspectivas e sentimentos revelados. Nurs 2003 fev; 57(6): 12-17.

2. Silva MJP da. Humanização em UTI. In: Cintra EA, Nushide VM, Nunes WA. Assistência de enfermagem ao paciente crítico. São Paulo (SP): Atheneu; 2000. p. 1-11.

3. Cianciarullo TI, Fugulin FMT, Andreoni S. A hemodiálise em questão: opção pela qualidade assistencial. São Paulo(SP): Ícone; 1998.

4. Orlando JMC. UTI: Muito além da técnica... a humanização e a arte do intensivismo. $6^{\text {a }}$ ed. São Paulo (SP): Atheneu; 2001.

5. Waldow VR. Cuidado humano: o resgate necessário. Porto Alegre (RS): Sagra Luzzatto; 1998.

6. Gomes AM. Enfermagem em unidade de terapia intensiva. São Paulo (SP): EPU; 1998.

7. Boemer MR, Rossi LRG, Nastari RR. A idéia de morte na unidade de terapia intensiva: análise de depoimentos. Rev Gaúcha Enferm 1989 jul; 10(2): 8-14.

8. Ministério da Saúde (BR). Conselho Nacional de Saúde. Resolução $n^{0} 196 / 96$ sobre pesquisa envolvendo seres humanos. Bioética 1996; 4(2):15-25.

9. Bardin L. Análise de conteúdo. Lisboa: Ed 70; 1977.

10. Koizumi MS, Kamiyama Y, Freitas LA. Percepção dos pacientes de unidade de terapia intensiva: problemas sentidos e expectativas em relação à assistência de enfermagem. Rev Esc Terapia Enferm USP 1979 abr/jun; 13(2): 135-45. fundamentada não apenas na técnica, mas também em valores pessoais, apreendendo ainda a compreensão do verdadeiro significado e abrangência do cuidado humano. É necessário direcionar a assistência ao conforto físico associado à prestação de cuidados que visam amenizar a dor e o sofrimento. Cuidar com compromisso, aplicando a prática com vistas à promoção da saúde.

Ainda segundo evidenciamos, para os profissionais de saúde, o momento da coleta de dados constituiu-se em uma oportunidade para refletir sobre sua missão de cuidar desses doentes; vê-los como seres no mundo inseridos em um contexto, procurando observar-lhes não somente as necessidades biológicas aparentes, mas também aquelas não evidenciadas, as mais ocultas. 0 processo reflexivo faz-nos repensar sobre nossas posturas acadêmicas, profissionais e pessoais. Reforça a importância do trabalho em equipe, buscando sempre humanizar o cuidado.

11. Silva LD. Cuidados ao paciente crítico: fundamentos para a enfermagem. $2^{\mathrm{a}}$ ed. Rio de Janeiro (RJ): Cultura Médica; 2003.

12. Oliveira FPT, Santos GS, Silva LS. A percepção do paciente sobre sua permanência na unidade de terapia intensiva. Nursing 2003 maio; 60(6): 37-42.

13. Sousa LNA, Padilha MICS. A humanização na UTI: um caminho em construção. Texto \& Contexto Enferm. 2000 maio/ago: 9(2): 324-35.

14. Ferreira $A B H$. Novo dicionário da língua portuguesa. $2^{\mathrm{a}}$ ed. Rio de Janeiro (RJ): Editores; 1998.

\section{Sobre as Autoras}

\section{Joselany Áfio Caetano}

Enfermeira, Doutora, Professora da Universidade Federal do Ceará (UFC).

\section{Enedina Soares}

Enfermeira, Professor Colaborador do Programa de PósGraduação da UNIRIO.

\section{Luciene Miranda de Andrade}

Professora, Mestra da Universidade de Fortaleza, Enfermeira do Instituto Dr. José Frota.

\section{Roberta Maria da Ponte}

Aluna do Curso de Graduação da Universidade Estadual Vale do Acaraú (UVA). 